\title{
Large-scale nuclear remodeling and transcriptional deregulation occur on both derivative chromosomes after Mantle Cell Lymphoma chromosomal translocation
}

Fatimata Bintou Sall ${ }^{1,2}$, Andrei Pichugin ${ }^{1}$, Olga Iarovaia ${ }^{3}$, Ana Barat ${ }^{1}$, Tatyana Tsfasman ${ }^{1}$, Caroline Brossas ${ }^{4}$, Marie-Noëlle Prioleau ${ }^{4}$, Eugeny V. Sheval ${ }^{5}$, Anastasiya A. Zharikova ${ }^{5}$, Julien Lazarovici ${ }^{6}$, Valérie Camara-Clayette ${ }^{7}$, Vincent Ribrag ${ }^{6,8}$, Marc Lipinski ${ }^{1}$, Yegor Vassetzky ${ }^{1,9}$ and Diego Germini ${ }^{1,10}$

${ }^{1}$ UMR9018, Université Paris-Saclay, CNRS, Gustave Roussy, Villejuif, France;

${ }^{2}$ Laboratoire d'Hématologie, Centre Hospitalier Universitaire Aristide Le Dantec, Université Cheikh Anta Diop, Dakar, Senegal;

${ }^{3}$ Institute of Gene Biology, Russian Academy of Sciences, Moscow, Russia;

${ }^{4}$ UMR7592, Université Paris Diderot, CNRS, Institut Jacques Monod, Paris, France;

${ }^{5}$ Belozersky Institute of Physico-Chemical Biology, Moscow State University, Russia

${ }^{6}$ Département d'Hématologie, Gustave Roussy, Université Paris-Saclay, Villejuif, France;

${ }^{7}$ AMMICa INSERMUS23/CNRS UMR3655, Translational Hematology Unit, Gustave

Roussy, Villejuif, France;

${ }^{8}$ Département des Innovations Thérapeutiques et Essais Précoces, Gustave Roussy, Université Paris-Saclay, Villejuif, France;

${ }^{9}$ Koltzov Institute of Developmental Biology, Russian Academy of Sciences, Moscow, Russia

${ }^{10}$ Corresponding author: germinidiego@gmail.com 


\begin{abstract}
Recurrent chromosomal translocations are found in many blood and solid cancers. Balanced translocations, frequent in lymphoid malignancies, lead to the formation of two aberrant derivative (der) chromosomes. This event often leads to overexpression of an oncogene. In many cases, the expression of an oncogene is not enough to produce a malignant phenotype; however, most part of the studies focus on the events involving the chromosome where the oncogene is located, but rarely the other der chromosome where other oncogenic alterations may potentially arise. Mantle cell lymphoma (MCL), an aggressive B-cell non-Hodgkin lymphoma, is a perfect example of this. In $85 \%$ of the cases, it is characterized by the translocation $\mathrm{t}(11 ; 14)$, which leads to the overexpression of cyclin D1 (CCND1) gene which results juxtaposed to the immunoglobulin heavy chain $(I G H)$ gene on the der14 chromosome. This feature alone is not sufficient to induce oncogenesis. Here we focused on the der11 chromosome. We demonstrated that expression of 88 genes located in a $15 \mathrm{mb}$ region close to the translocation breakpoint on the der11 was deregulated both in the GRANTA-519 MCL cell line and in B-cells from MCL patients. We found that a large segment of der11containing deregulated genes was relocated from its normal position in the nuclear periphery towards the center of the nucleus in close proximity to the nucleolus where the abundant nucleolar protein nucleolin binds a subset of genes located close to the breakpoint and activates their expression. This finding allowed to identify new potential oncogenes involved in MCL and the mechanisms of their upregulation.
\end{abstract}




\section{INTRODUCTION}

Mantle cell lymphoma (MCL) is a non-Hodgkin lymphoma characterized by an uncontrolled proliferation of the B-cells located in the outer edge of a lymph node (mantle zone). It represents $8 \%$ of all lymphomas in Europe (Vose, 2017). It has a poor prognosis with an average survival rate of five years (Skarbnik and Goy, 2015). Despite significant advances in treatment (Camara-Clayette et al., 2012), MCL still remains an incurable disease (Campo and Rule, 2015). Moreover, its annual incidence has increased during recent decades (Epperla et al., 2017).

It is characterized by a specific $\mathrm{t}(11 ; 14)(\mathrm{q} 13$; q32) (Bentz et al., 2000; Li et al., 1999) translocation where the 11q13 region (encoding for over 300 genes) is recombined with the Immunoglobulin Heavy Chain $(I G H)$ locus on chromosome 14.

This translocation leads to the over-expression of the gene encoding for the G1/S specific Cyclin D1 (CCND1) that is not expressed in quiescent B lymphocytes (Bosch et al., 1994; Dreyling et al., 1997).

However $\mathrm{t}(11 ; 14)$ can be also detected in healthy people's blood cells (Hirt et al., 2004) and expression of CCNDI under the control of different known IGH enhancers in transgenic mice is not sufficient for tumor development (Fiancette et al., 2010; Lovec et al., 1994). Indeed it seems that CCND1 is not the only gene affected in MCL and recurrent mutations are found in other genes belonging to different pathways and cellular processes e.g. cell cycle (ATM), epigenetic regulation (MLL2 and 3), NF-kB pathway (BIRC2 and 3) (reviewed in (Ahmed et al., 2016)). Some MCL cases exist lacking CCND1 overexpression but carrying secondary alteration as SOX11overexpression (Jares et al., 2012). These data point out that additional oncogenic alterations are necessary to develop a malignant phenotype.

Data previously obtained in our laboratory show that the CCND1 locus, normally located at the periphery of the nucleus, after the $\mathrm{t}(11 ; 14)$, in MCL cell lines or in lymphoma cells from patients, is regularly found close to the center of the nucleus and/or associated to the nucleolus. In the surroundings of the nucleolus, foci of active polymerase II, therefore regions of transcriptionally active chromatin, and a range of potential transcription factors have been found. For instance nucleolin, a major nucleolar protein, which forms, together with hnRNP D, the B cells-specific heterodimeric transcription factor LR1, may be involved in activation of oncogenes in lymphomas (Allinne et al., 2014). 
Following a chromosomal translocation, changes in spatial gene localization and nuclear reorganization occur, inducing alterations in gene expression and potentially leading to additional events necessary for oncogenesis (reviewed in (Harewood and Fraser, 2014)). In the present work, we looked for possible oncogenic modifications in genomic regions other than the CCND1 and the der14 chromosome and we focused our attention on the events involving the der11 chromosome where only a small portion of the chromosome 14 is translocated.

We describe here new features specific of MCL and potentially linked to the malignant transformation. We have shown in MCL cells (in vitro and from MCL patients) a massive deregulation of the expression of genes located on the chromosome 11 close to the translocation breakpoint. Most of these genes were located on the der11 after the $t(11 ; 14)$. We explained this event by showing that the der11 chromosome is relocated in close proximity to the nucleolus where the nucleolin directly binds to chromatin, modulating gene expression. The same nuclear reorganization was also found in B-cells from MCL patients harboring the $\mathrm{t}(11 ; 14)$. Our results describe novel genomic and transcriptomic alterations for MCL, a possible role played by nucleolin in inducing potential lymphomagenic alterations and provide potential new targets for the amelioration of the prognosis for MCL. 


\section{RESULTS}

Analysis of clustered gene expression in MCL reveals a large domain of upregulated genes adjacent to the translocation point on der11chromosome.

We first wanted to determine whether the $t(11 ; 14)$ perturbs the expression of genes other than CCND1 in the vicinity of the translocation breakpoint.

We have performed RNA-seq of MCL cell lines (GRANTA-519, carrying the $\mathrm{t}(11 ; 14)$ ) and RPMI8866 lymphoblastoid cell lines (LCL) used as a control. Gene expression in GRANTA519 was compared to LCL RPMI8866 and the genes significantly upregulated (adjusted p value $<0.05)$ were mapped on each chromosome. We found that a total of 286 genes were significantly upregulated on the chromosome 11. After the translocation, the portion of genes located on der11 in close proximity to the CCND1 (Figure 1A, in green) shows a more deregulated pattern as compared to the genes located on the der14 (Figure 1A, in red). Dividing the chromosome 11 in equal portions of $15 \mathrm{mb}$, we found that the greatest percentage of upregulated genes was located in the region surrounding the translocation breakpoint compared to the rest of the chromosome (Figure 1B). That region contains genes mainly located on the der11. Such a relatively high transcriptional deregulation region cannot be found within other chromosomes (Supplementary Figure 1).

Replication timing of genomic regions correlates with gene transcription and changes in nuclear position. Active transcription coincides with a switch from late to early replication timing (Rhind and Gilbert, 2013; Rivera-Mulia et al., 2015). In order to verify this correlation in our experimental model, we analyzed the DNA replication timing in GRANTA-519 and in LCL RPMI8866 as a control. Cells labeled with BrdU were sorted into two S-Phase fractions (early and late S-Phase) and immunoprecipitated with an anti-BrdU antibody, amplified, differentially labeled, and co-hybridized onto a whole human genome oligonucleotide microarray. The replication-timing profile represented here is obtained by the $\log _{2}$-ratio of the abundance of each genomic probe in the early and late S-phase fractions, revealing early and late replicated domains.

We observed a significant shift to early replication timing surrounding the CCND1 gene in GRANTA-519 (purple lines) in contrast to the LCL RPMI8866 (blue lines) (Figure 1C). This $10 \mathrm{Mb}$ modified region (black arrow in Figure 1C) moves from a late S-Phase to a Mid-SPhase replication timing (Figure 1C).

The replication timing modification covers a wide region upstream and downstream the $C C N D 1$ gene covering from the $11 \mathrm{q} 13.2$ to the $11 \mathrm{q} 13.4$ loci. This region coincides to the one 
where the massive gene deregulation was observed in the RNA-seq, thus supporting our data. The replication timing profile at the CCND1 locus corresponds to an average of the replication timing of the two alleles (wild type and translocated), leading to an underestimation of the replication timing shift due to the translocation. For this reason, we can assume that the replication timing of the translocated allele of chromosome 11 at the translocation breakpoint moves from late-S-phase to early-S-phase, while the other allele keeps the same late replication timing as the LCL RPMI8866.

To understand if the data obtained in vitro has relevance in vivo, we performed RNA-seq on B-cells purified from four MCL patients in leukemic phase. Eighty-eight genes were commonly upregulated in GRANTA-519 and in the four patients compared to the LCLRPMI8866 (Figure 2). Forty-eight percent of them (42 genes) were located in the same $15 \mathrm{mb}$ region surrounding the translocation breakpoint while the remaining $52 \%$ was distributed throughout the whole chromosome 11 (Figure 2).

Among the deregulated genes located on the der11 close to the breakpoint there are several that has been correlated to multiple cancer development such MEN1 implied in chromatin remodelling, RAD9A involved in DNA damage response, CTSF involved in apoptosis regulation (Bassi et al., 2016; Covington and Fuqua, 2014; Ji et al., 2017; Lee et al., 2004),GSTP1 found deregulated in other cases of MCL and implicated in the cell detoxification from xenobiotics (Yuan et al., 2008).

This global overexpression pattern specific of MCL describes transcriptional alterations other than $C C N D 1$ and can hardly be explained by the action of a single enhancer but rather could be a result of a large-scale post-translocation modification. Alterations in the nuclear position of chromosomal loci can explain such transcriptional modifications due to a newly acquired vicinity to nuclear region rich in transcriptional factor or transcriptionally active as the nucleolus. Thus, we next investigated the nuclear positioning of translocated and nontranslocated loci.

\section{Der11 chromosome relocates next to the nucleolus after the $t(11 ; 14)$.}

We have studied, using the immuno-3D-FISH technique, the nuclear organization in MCL (GRANTA-519) and control cell lines LCL RPMI8866 and its changes after the $\mathrm{t}(11 ; 14)$. Der11 chromosome was visualized in 3D-FISH as colocalized signals of GSTP1 gene locus (colored in green) located on chromosome 11 upstream to the translocation breakpoint and the telomeric portion of the chromosome 14 ("Tel14IGH" - in red) (Supplementary Figure 2). 
We divided the nucleus in 10 concentric volumes where the volume "1" represents the periphery of the nucleus and the volume "10" represents its center. As shown in Figure 3A (top panels) in control cells LCL RPMI8866, in the absence of $\mathrm{t}(11 ; 14)$, the GSTP1locusis mostly found between the center and the periphery of the nucleus (being mostly located in volume "5") while the $I G H$ locus is closer to the nucleus center (mostly located in volumes "7, $8 ")$. In GRANTA-519 cells the same loci located on the der11 chromosome relocate as compared to control cells, both moving towards the nucleus center (mostly located in volumes "8-9", Figure 3A bottom panels).

We have previously shown that in MCL and other cancer cells, the perinucleolar region is enriched in active transcription zones called «transcription factories» (Allinne et al., 2014; Razin et al., 2011). The movement towards transcriptional active areas could correlate with transcriptional deregulation as that observed in genes located on the der11. Thus, we checked if the GSTP1 movement in the nuclear space after the translocation corresponds to a relocalization towards the nucleolus. We measured and compared the distance of each GSTP1 signal colocalized, in GRANTA-519 (der11), and not colocalized, in LCL RPMI8866, with Tel14IGHto the closer nucleolus (visualized by staining the major nucleolar protein, nucleolin). We found that in GRANTA-519 cells the percentage of cells where the GSTP1 locus on der11 is closer than $1 \mu \mathrm{m}$ to the nucleolus is significantly higher than in control LCL RPMI8866 (74.2 \pm 3.5 vs 27.6 \pm 4.7 ) (Figure 3B). A representative 3D-FISH image of this event is shown in Figure 3C. Also the average distance from the nucleolus of the GSTP1 loci on the der11 is $0.73 \pm 0.04 \mu \mathrm{m}$ which is significantly closer compared to normal LCL RPMI8866 (average distance $=1.94 \pm 0.07 \mu \mathrm{m})($ Supplementary Figure 3).

The demonstrated relocalization in the nuclear space of the loci on theder11 chromosome close to the nucleolus can potentially expose them to a transcriptional activation and to the action of transcription factors that can explain the overexpression of the cluster of genes in MCL described above.

\section{Der11 proximity to the nucleolus is present also in circulating MCL B-cells from patients.}

To understand whether our in vitro findings could be relevant to clinical conditions, we then focused our attention on circulating B-cells isolated from MCL patients. The comparison between the position of the der11 and the non-translocated loci within the same sample was performed as described above by using the 3D-FISH technique. In three out of four MCL 
patients the percentage of GSTP1 signals located at less than $1 \mu \mathrm{m}$ from the nucleolus is significantly higher for the loci on the der11 than on the intact 11 chromosome (Figure $\mathbf{4 A}$ ). Considering the means of all the four patients, the percentage of the GSTP1 signals closer than $1 \mu \mathrm{m}$ to the nucleolus is higher when GSTP1 is on der11 than when is on the intact

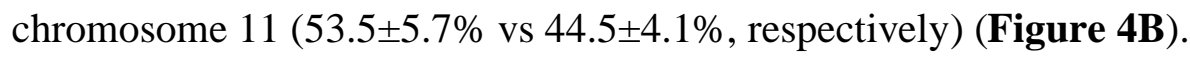

These results obtained from B-cells purified from MCL patients support the previously described in vitro results.

\section{Nucleolin activates the transcription of der11 overexpressed genes}

LR1 is a B-cell-specific transcriptional factor, binding a known DNA consensus sequence GNCNAG(G/C)CTG(A/G) (Hanakahi et al., 1997)and capable of regulating transcription in activated B-cells. LR1 is composed by two polypeptides of 106 and $45 \mathrm{kDa}$. The $106 \mathrm{kDa}$ component is the nucleolin (Hanakahi et al., 1997).

Thus, we wanted to understand if the newly acquired proximity to the nucleolus and, consequently, to the nucleolin of the der11 chromosome could play a role on regulation of gene transcription.

We have performed ChIP-seq analysis targeting nucleolin on GRANTA-519 and LCL RPMI8866. Binding site analysis performed using MEME (Bailey and Elkan, 1994) revealed a motif consistent with the published one and a novel one (Supplementary Figure 4). Bioinformatic and Integrated Genome Viewer analysis revealed peaks corresponding to nucleolin binding sites in the same $15 \mathrm{mb}$ region where the massive gene expression regulation was found. The number of peaks found in that region in LCL RPMI8866 and GRANTA-519 did not differ significantly ( 32 on average between the two replicates). Nevertheless, peaks present only in GRANTA-519 were found in correspondence of significantly upregulated genes (Figure 5). Interestingly those genes were clusterized at the beginning (e.g. $C D 6$ ), in the middle (e.g. EHD1) or close to the CCND1 (e.g. CPT1A) of the $15 \mathrm{mb}$ region.

To further confirm the transactivating role of nucleolin, we ectopically expressed GFPnucleolin in HEK cells. GFP+ cells were sorted, and the expression of genes located in the 15 $\mathrm{mb}$ region and commonly deregulated in GRANTA-519 cells and the four MCL patients was analyzed and compared to non-transfected HEK. In transfected cells the expression of the gene encoding for the nucleolin was $210.4 \pm 38.3$ fold higher than non-transfected HEK (Figure 6A). The presence of a higher amount of nucleolin significantly increased the 
expression of CD6, PYGM, CTSF andCPTIA (Figure 6B). In correspondence of CD6 and CPT1A, peaks in ChIP-seq analysis were also found. The expression of genes located on the chr11 (DAK and RTN3) or on other chromosomes (SOD1 and RUNX1T1) that was unaffected in the RNA-seq remained unchanged in transfected HEK (Figure 6B, rightmost histograms), thus confirming the specific effect of the nucleolin. 


\section{DISCUSSION}

Chromosomal translocations are the result of two simultaneous DNA double-strand breaks in different chromosomes followed by reciprocal erroneous rejoining of DNA ends. In the case of balanced translocations, frequent in lymphoid malignancies, two aberrant chromosomes are formed and called derivative (der) chromosomes (Lieber, 2016). Recurrent chromosomal translocations are found in blood and certain solid tumors.

After a translocation one of the most recurrent effects is the overexpression of an oncogene following its juxtaposition with a highly expressed gene. This is the case for example for Burkitt lymphoma, Follicular lymphoma or Mantle cell lymphoma where MYC, BCL2 and $C C N D 1$, respectively, result overexpressed following their erroneous joining next to an immunoglobulin gene locus. These recurrent chromosomal aberrations often serve as a marker of the tumor.

The presence of a translocation does not inevitably mean oncogenic transformation, indeed genomic translocations are also found in healthy individuals, thus meaning that additional mutations and alterations are required to produce a malignant phenotype (Aplan, 2006). At the same way also oncogene overexpression occurring after the translocation is not enough to produce a malignant phenotype and additional alterations should arise (Grumolato and Aaronson, 2014).

This is true for MCL for which it has been demonstrated that CCND1 (located on the chromosome 11) alone is not enough to induce the malignant transformation and additional alterations involving cell cycle, DNA damage response or epigenetic modifications are required (Peterson et al., 2019). An understanding of the events and the mechanisms leading to lymphomagenesis is still lacking.

We have found that common genes are deregulated in vitro and in MCL patients on the chromosome 11 and half of them was concentrated in a relatively small region of $15 \mathrm{Mb}$ next to the translocation breakpoint.

Among the deregulated genes we found genes implicated in DNA damage and repair (ATM, MRE11 and RAD9A) or others that has already been described as deregulated or markers or mutated in lymphomas or other cancers (AHNAK, CD6, CTSF, CPTIA, MEN1) or associated to B-cells proliferation (CYB561A3, MAP3K11) (Hartmann et al., 2008; Hoster et al., 2008; Knackmuss et al., 2016; Melone et al., 2018; Pasqualucci et al., 2011; Rizzatti et al., 2005; Thieblemont et al., 1999). 
Consistently with other studies, also the glutathione S-transferases P1 gene (GSTP1) gene was upregulated. Proteins from GSTs family play an important role in the cell detoxification from xenobiotics that may be carcinogenic (Seidegård and Ekström, 1997) and GSTP1 expression level deregulation has already been associated to prostate, breast, liver, renal, and endometrial carcinomas (Yuan et al., 2008) and to MCLs (Bennaceur-Griscelli et al., 2004; Bosch et al., 1994).

According with other findings, also genes located on chromosomes other than the 11 were found deregulated as TP53, SOX11, BCL family members and RB1 (Kienle et al., 2007; Meggendorfer et al., 2013; Rummel et al., 2004; Sakhdari et al., 2019)

The obtained results were also confirmed by data mining of transcriptomic data from Gene Expression Omnibus (GEO) of 15 conventional MCL patients' samples composed of Peripheral blood CD19+ tumor cells (GSE16455) and of 3 naive B-cells samples (GSE12366). We have found that the expression of genes located in two short regions (4 Mb) on chromosomes 7 and 9 and one long region $(15 \mathrm{Mb})$ on the chromosome 11 in proximity of the translocation breakpoint, mainly located on the der11 were significantly deregulated. This event was specifically occurring in MCL after the $t(11 ; 14)$, indeed performing the same analysis on data obtained from Follicular Lymphoma cells, the expression of the genes located in the same regions was not significantly changed.

For CCND1 overexpression mechanisms in MCL, different hypothesis have been formulated (Allinne et al., 2014; Liu et al., 2008). It is assumed that it depends on the potent E $\mu$ enhancer located upstream of $C C N D I$ in the $I G H$ locus even if the distance between the two partners could be several hundred kilobases (Degan et al., 2002; Greisman et al., 2012). Our laboratory previously proposed that the CCND1 transcriptional activation in MCL was related to the repositioning of the rearranged $I G H-C C N D I$-carrying chromosome (der14) in close proximity with the nucleolus, a nuclear territory with abundant nucleolin acting as transcriptional factor and PolII molecules.

Translocations can lead to large scale modification of chromosome territory position affecting the expression of many different genes (Harewood et al., 2010).

Analysis of the nuclear positioning and transcriptional modifications of the der11, one of the chromosomes generated by the translocation $\mathrm{t}(11 ; 14)$, carrying a large portion of the chromosome $11(\sim 71 \mathrm{Mb})$ and a small part of chromosome $14(\sim 10 \mathrm{Mb})$, revealed that 
surprisingly the presence on this chromosome of a small fragment of the chromosome 14 is enough to induce a large movement of a large portion of the chromosome 11 in the nuclear space. We observed that the der11 relocates in close proximity to the nucleolus where the nucleolin, component of the LR1 transcription factor, can directly bind chromatin and lead to the deregulation of gene expression. We found the same transcriptional deregulation and nuclear remodelling in four MCL patients in leukemic phase.

In summary, in the present and previous works from our laboratory, we provided novel proofs of genes as possible markers for MCL other than CCNDI and describe large scale chromatin modification leading to a nucleolin dependent massive gene deregulation in specific regions of der14 and der11 chromosomes.

\section{ACKNOWLEDGEMENTS}

This research was supported by grants from the ANRS, INSERM (ENVIBURKITT) and La Ligue Contre le Cancer (M27231). We gratefully acknowledge the imaging and cytometry platform of the Gustave Roussy Institute for the technical support.

\section{CONFLICT OF INTEREST}

The authors declare no conflict of interest 


\section{MATERIALS AND METHODS}

\section{Cell cultures}

The human Mantle cell lymphoma (MCL) cell line GRANTA-519 waskept in culture in RPMI 1640 medium supplemented with 10\% heat-inactivated FBS 2 mM L-glutamine and $1 \%$ penicillin/streptomycin antibiotics $($ Gibco®, Thermo Fisher Scientific, Carlsbad, CA, USA). For cultivating the lymphoblastoid cell line (LCL) RPMI8866 this medium was further supplemented with $2 \%$ Glucose, and $1 \mathrm{mM}$ Sodium pyruvate (Gibco®, Thermo Fisher Scientific, Carlsbad, CA, USA).

Peripheral blood mononuclear cells (PBMCs) were isolated from blood of MCL patients by Pancoll (PAN biotech, Aidenbach, Germany, lymphocytes separation medium) density gradient centrifugation. B lymphocytes were obtained by negative cell selection using the MagniSort Human B-cell enrichment kit II (Thermo Fisher Scientific, Carlsbad, CA, USA) according to the manufacturer's protocol. They were kept in culture for $24 \mathrm{~h}$ into RPMI medium supplemented with $10 \%$ heat-inactivated FBS and $1 \%$ penicillin/streptomycin antibiotics(Gibco®, Thermo Scientific, Carlsbad, CA, USA)before collecting them for further analysis.

Human Embryonic Kidney (HEK-293) cells were cultivated in DMEM (Gibco®, Thermo Scientific, Carlsbad, CA, USA) supplemented with 10\% FBS,2mM glutamine and 1\% penicillin/streptomycin.

All cells were cultured at $37^{\circ} \mathrm{C}$ in a humidified $5 \% \mathrm{CO} 2$ atmosphere.

\section{Mantle cell lymphoma patients}

Whole blood samples were obtained from four individuals followed in the Department of Medical Oncology, Institut Gustave Roussy, Villejuif, France. Blood samples were collected in agreement with French law and informed consent was obtained from all subjects.

\section{RNA isolation, library preparation and RNA sequencing}

RNA was extracted from LCL RPMI8866, GRANTA-519 and B-cells purified from four MCL patients using the NucleoSpin ${ }^{\circledR}$ RNA II kit according to the manufacturer's protocol (Macherey-Nagel, Oensingen, Switzerland). A minimum of $2 \mu \mathrm{g}$ per samples were used for analysis. Samples were processed and analyzed at NovoGene Co., Beijing, China. Quality and quantity were assessed with Qubit Fluorometer, poly-A enriched library prepared, samples sequenced using an Illumina PE150 and analyzed. 


\section{Replication timing analysis}

LCL RPMI8866 and GRANTA-519 were pulse labeled with BrdU and sorted into two SPhase fractions (early and late S-Phase). BrdU labeled nascent DNA from early and late fractions were immunoprecipitated with an anti-BrdU antibody, amplified, differentially labeled, and co-hybridized onto a whole human genome oligonucleotide microarray. The $\log _{2^{-}}$ ratio of the abundance of each genomic probe in the early and late S-phase fractions generates a replication-timing profile that reveals early and late replicated domains.

Replication timing analysis was carried out as previously described (Hassan-Zadeh et al., 2012). Briefly, immunoprecipitated nascent strands were amplified by whole-genome amplification kit (Sigma Aldrich, St Louis, MO, USA). After amplification, early and late nascent strands were labeled with Cy3 and Cy5 ULS molecules using the Genomic DNA labeling Kit (Agilent, Santa Clara, CA, USA) following manufacturer's instructions. The hybridization was performed according to the manufacturer instructions on human CGH microarrays that cover the whole genome. Microarrays were scanned with an Agilent's HighResolution C Scanner using a resolution of $2 \mu \mathrm{m}$ and the autofocus option. Feature extraction was done with Feature Extraction 9.1 software (Agilent, Santa Clara, CA, USA). For each experiment, the raw data sets were automatically normalized by the Feature extraction software. Analysis was performed with Agilent Genomic Workbench 5.0 software. The log2ratio timing profiles were smoothed using the Moving Average option of the Agilent Genomic Workbench 5.0 software with the linear algorithm and $200 \mathrm{~kb}$ windows.

\section{Immuno-3D-FISH}

"RainbowFISH" probes (Empire Genomics, Buffalo, NY, USA)) used for hybridization and staining of human chromosome loci 14q32.33 (IGH gene locus) and 11q13.2 (GSTP1 gene locus) were labeled with SpectrumOrange and SpectrumGreen respectively. Cells were immunofluorescently stained with the rabbit anti-nucleolin antibody (Sigma-Aldrich). Nuclei were stained with DAPI diluted into the Vectashield mounting medium (Vector Laboratories, Burlingame, CA, USA). Immuno-3D-FISH was performed as previously described (Germini et al., 2017).

\section{Microscope image acquisition and analysis}

Images were acquired using a TCS SP8 confocal microscope (Leica Microsystems, Berlin, Germany) with a $63 \mathrm{X}$ oil immersion objective. Z-stacks were acquired using a frame size of 
$1024 \times 1024$, and $0.5 \mu \mathrm{m}$ z-steps, with sequential multitrack scanning using the $405,488,543$, $633 \mathrm{~nm}$ laser wavelengths for detecting DAPI (cell nuclei), SpectrumGreen (GSTP1), SpectrumOrange $(I G H)$ and far-red (Nucleolin). Radial position and distance from the closest nucleolus of gene loci was calculated using the Bitplane ${ }^{\circledR}$ Imaris (Zurich, Switzerland) program.

\section{HEK cells transfection and sorting}

400,000 cells were plated in 6-well plate in complete DMEM medium. The day after when cells reached approximately $70 \%$ of confluence they were transfected with $3 \mu \mathrm{g}$ of the PEGFPC1 plasmid (Addgene \#28176) using the Viafect reagent (Promega, Madison, WI, USA) following manufacturer's protocol. Transfection was carried out for $48 \mathrm{~h}$ and then GFP+ cells sorted using the ARIA III cell sorter (Becton Dickinson, Franklin Lakes, NJ, USA).

\section{RT-qPCR}

Total RNA was extracted from cells using the NucleoSpin ${ }^{\circledR}$ RNA II kit according to the manufacturer's protocol (Macherey-Nagel). Sixty nanograms of total RNA were reverse transcribed by using the RevertAid H Minus First Strands cDNA Synthesis Kit with oligo(dT) primers (Thermo Scientific). The obtained cDNA was amplified using specific primers (Supplementary Table 1) and the PowerUp SYBR Green Master Mix (Thermo Scientific). Expression of target genes was analyzed using the $2^{-\Delta \Delta \mathrm{Ct}}$ method with normalization with GAPDH and comparison of expression between non transfected (Control) and GFP+ cells. For quantification, expression levels were set to 1 in control.

\section{Chromatin Immunoprecipitation (ChIP)-seq}

Thirty millions cells were fixed with $1 \%$ formamide for 1 minute in a rotating wheel. Fixation reaction was stopped by adding $0.125 \mathrm{M}$ glycin. Cells were then pelleted at $4^{\circ}, 1400 \mathrm{xg}$ for 10 minutes and washed 3 times in ice cold 1XPBS. At the third wash, $0.5 \%$ PIC and $0.5 \mathrm{mM}$ of PMSF were added. Cells were pelleted and resuspended in $1 \mathrm{~mL}$ of lysis buffer (10mM Tris$\mathrm{HCl}, 150 \mathrm{mM} \mathrm{NaCl}, 0.5 \mathrm{mM}$ EDTA, 0.5\% NP-40, 0.5\% PIC, 0.5mM PMSF, water). Cell lysate was transferred to a dounce homogenizer to allow the separation between cell cytoplasm and nuclei and dounced 10 times. Nuclei are then pelleted by centrifugation at $5000 \mathrm{xg}$ for 5 minutes at $4^{\circ}$ and resuspended in nuclear lysis buffer $(50 \mathrm{mM}$ Tris- $\mathrm{HCl}, 10 \mathrm{mM}$ EDTA, $1 \%$ SDS, $1 \%$ PIC, 1mM PMSF, water). Nuclei were sonicated in ice in a Vibra Cell sonicator (Newtown, CT, USA) with25 cycles of $30 \mathrm{sec}$ pulse-on, $30 \mathrm{sec}$ pulse-off, 75\% 
amplitude. The non-solubilized material was removed by centrifugation at $15,000 \mathrm{~g}$ for 10 min. The desired size of chromatin fragments (100-500 bp) was monitored by electrophoresis in a $1 \%$ agarose gel after reverse crosslinking (dilution $1: 4$ in water and adding $0.250 \mathrm{M}$ of $\mathrm{NaCl}$ keeping at $65^{\circ}$ overnight in a thermalcycler), treatment with $100 \mu \mathrm{g} / \mathrm{ml}$ RNase A $\left(37^{\circ}\right.$ for 15 minutes) and $50 \mu \mathrm{g} / \mathrm{ml}$ proteinase $\mathrm{K}$ and purification using the PCR cleanup kit (MachereyNagel).

Chromatin immunoprecipitation was performed as following: $25 \mu \mathrm{g}$ of chromatin solution was incubated at $4^{\circ}$ overnight with $25 \mu 1$ of the PrG-Dynabeads (Thermo Scientific), $3 \mu \mathrm{g}$ of antibody (rabbit-anti Nucleolin, Sigma-Aldrich), ChIP Buffer I (Active Motif, La Hulpe, Belgium), 1X PIC and water. The following day the beads were washed once with ChIP Buffer I and twice with ChIP Buffer II (Active Motif) before elution with 50mM Glycine (pH 2.8) for 15 minutes at room temperature. Elution was stopped by adding Tris base $1 \mathrm{M}$ (pH10.4). By using a magnet, supernatant was kept, reverse cross-linked, purified and quantified by using a Nanodrop (Thermo Scientific).

Before sequencing, effective ChIP was checked via PCR amplification of known positive and negative targets of the nucleolin by normalizing the results using the input sample.

A minimum of 100ng of ChIP DNA were sent to NovoGene for sequencing where quality and quantity were assessed with Qubit Fluorometer, library prepared, samples sequenced using an Illumina PE150 and analyzed.

\section{Statistical analyses}

The Student t-test was used to compare means. All tests were performed using the GraphPad Prism 5 software (GraphPad software Inc., La Jolla, CA, USA). 


\section{FIGURE LEGENDS}

Figure 1. Gene transcription and replication timing is perturbed on the chromosome 11 after the $t(11 ; 14)$ translocation.

(A) Profile of gene transcription upregulation along chromosome 11 in GRANTA-519 cells compared to LCL RPMI8866. RNA was extracted from GRANTA-519 cells and LCL RPMI 8866, used as a control, and RNA seq performed. Upregulated genes were mapped along the chromosome 11, on the $\mathrm{Y}$ axis $\log 2$ fold change (FC) of each gene is reported from the first upregulated gene ("1" on the $\mathrm{X}$ axis) on the p arm of the chromosome 11 to the last one on the telomeric region. $\log 2 \mathrm{FC}$ of the genes located upstream (on the der11 after the $\mathrm{t}(11 ; 14)$ ) and downstream (on the der14 after the $\mathrm{t}(11 ; 14)$ ) of the CCND1 are represented in green and red, respectively.

(B) Percentage of deregulated genes in seven non overlapping $15 \mathrm{mb}$ regions of the chromosome 11. The percentage was calculated on the total number of upregulated genes of the chromosome 11. Genes located upstream (on the der11 after the $t(11 ; 14)$ ) and downstream (on the der14 after the $t(11 ; 14)$ ) of the $C C N D 1$ are represented in green and red, respectively. The red and green histograms represent the percentage of upregulated genes in the $15 \mathrm{mb}$ surrounding the CCND1.

(C) Replication timing profiles at the region surrounding the translocation breakpoint on the chromosome 11. The profiles are represented with two light blue lines for LCL RPMI8866 and two violet lines for MCL cells GRANTA-519. Cells were sorted into two fractions of SPhase (early and late S-Phase). Pulse labeled BrdU nascent DNA from each fraction was recovered by immunoprecipitation and differentially labeled before co-hybridization to a human genome $\mathrm{CGH}$ microarray, containing one 60 -mer oligonucleotide probe every $13 \mathrm{~Kb}$. The $\log 2$-ratio (early/late) of the abundance of each probe in the early and late S-phase is shown. The timing profiles were smoothed using the Moving Average option of the Agilent Genomic Workbench 6.5 software with the triangular algorithm and $500 \mathrm{~kb}$ windows. Fast replicating genes are represented in red while in green the slow replicating ones. The black arrow highlight region where the replication timing shift is more evident.

Figure 2. RNA-seq in GRNATA-519 cells and in B-cells from MCL patients reveals commonly upregulated genes. RNA-seq was performed on RNA extracted from GRANTA519 cells, B-cells purified from MCL patients and LCL RPMI8866. All the transcriptomes were compared with the transcriptome of LCL RPMI8866. Upregulated genes from all comparisons were mapped on the different chromosomes. Upregulated genes located on the 
chromosome 11 are represented. The overlapping area among GRANTA-519 and the four MCL patients represents the commonly upregulated gene $(n=88)$. At the bottom is schematically represented where these genes are distributed along the chromosome 11 . The two black lines delimit the $15 \mathrm{mb}$ region surrounding the translocation breakpoint (represented by a red line). All RNA-seq were performed in triplicates.

Figure 3. After the $t(11 ; 14)$, translocated alleles move in the nuclear space in close proximity with the nucleolus.

(A) Radial distribution of the terminal part of the $I G H$ gene locus (chromosome 14) and of the GSTP1 locus (chromosome 11) in nuclei from MCL cells GRANTA-519 (where at least one allele of these loci is translocated in the $\mathrm{t}(11 ; 14))$ and LCL RPMI8866 where they do not translocate. $\mathrm{X}$ axis, distribution of fluorescent foci in 10 nuclear fractions of equal volume from the periphery (" 1 ", left) to the center ("10", right) of the nucleus; Y-axis, percentage of fluorescent foci in corresponding fraction. The radial position of IGH and GSTPI loci is schematically represented in the two pictures on the right. The triangle represents a portion of the nucleus divided into 10 equal volumes. The red $(I G H)$ and green $(G S T P 1)$ dots are placed in the nuclear fractions where the highest amount of signals was found. (B) Percentage of signals whose distance to the nucleolus is lower or equal to $1 \mu \mathrm{m}$. Results are represented as means \pm SEM. ***: p<0.001. A minimum of 216 loci were analyzed. (C) Representative 3DFISH images showing non translocated (LCL RPMI8866, top panels) and colocalized/translocated (GRANTA-519, bottom panels) IGH (red) and GSTP1 (green) gene loci in cell nuclei. Red and green colocalized signals determined the translocated alleles (der11). The square in the lower merge panel points to colocalized alleles. Nucleolus is visualized by nucleolin staining and represented in blue. Scale bar, $5 \mu \mathrm{m}$.

Figure 4. Der11 chromosome is closer to the nucleolus in MCL patients. (A) The percentage of translocated (Der11, grey histograms) and non-translocated GSTP1loci (Chr11, white histograms) closer than $1 \mu \mathrm{m}$ to nucleolus was calculated in B-cells purified from four MCL patients. *: $\mathrm{p}<0.05$. (B) Means of these percentages were compared using the t-test. *: $\mathrm{P}<0.001$.

Figure 5. Nucleolin binds in proximity of transcriptional deregulated genes. Integrated Genome Viewer visualization of nucleolin peaks are shown in GRANTA-519(upper lane) or LCL RPMI8866 (lower lane). ChIP-seq experiment was performed in duplicate. The 
nucleolin profiles of the CD6 and of the CPT1A locus are shown. The red lines are drawn in correspondence of the gene locus position on the chromosome 11 and the red arrows highlights the peaks observed in GRANTA-519 and not in LCL RPMI8866.

Figure 6. Ectopic expression of nucleolin induces overexpression of genes located close to the translocation breakpoint. Analysis of Nucleolin (A), CD6, AHNAK, RASGRP2, PYGM, CTSF, CPT1A, DAK, RTN3, SOD1 and RUNX1T1 (B) transcription in HEK cells transfected with a nucleolin encoding plasmid (grey histograms) or non-transfected (controls, white histograms). The transcription of the target genes was measured by qRT-PCR. Fold change expressions are in comparison with controls and after normalization vs. GAPDH. CD6, AHNAK, RASGRP2, PYGM, CTSF, CPTIA are located on the chromosome 11 and upregulated in the RNA-seq analysis, DAK, RTN3,SOD1 and RUNX1T1 served as controls as they were not deregulated in the RNA-seq analysis and are located on chromosomes 11 (DAK, RTN3), 21 (SOD1) and 8 (RUNX1T1). Data are means \pm SEM. ***: p<0.001; **: $\mathrm{p}<0.01 * ; \mathrm{p}<0.05$. 
bioRxiv preprint doi: https://doi.org/10.1101/2019.12.30.882407; this version posted April 15, 2020. The copyright holder for this preprint (which was not certified by peer review) is the author/funder, who has granted bioRxiv a license to display the preprint in perpetuity. It is made available under aCC-BY-NC-ND 4.0 International license.

\section{REFERENCES}

Ahmed, M., Zhang, L., Nomie, K., Lam, L., and Wang, M. (2016). Gene mutations and actionable genetic lesions in mantle cell lymphoma. Oncotarget 7, 58638-58648.

Allinne, J., Pichugin, A., Iarovaia, O., Klibi, M., Barat, A., Zlotek-Zlotkiewicz, E., Markozashvili, D., Petrova, N., Camara-Clayette, V., Ioudinkova, E., et al. (2014). Perinucleolar relocalization and nucleolin as crucial events in the transcriptional activation of key genes in mantle cell lymphoma. Blood 123, 2044-2053.

Aplan, P.D. (2006). Causes of oncogenic chromosomal translocation. Trends Genet. 22, 46-55.

Bailey, T.L., and Elkan, C. (1994). Fitting a mixture model by expectation maximization to discover motifs in biopolymers. Proceedings. Int. Conf. Intell. Syst. Mol. Biol. 2, 28-36.

Bassi, C., Li, Y.T., Khu, K., Mateo, F., Baniasadi, P.S., Elia, A., Mason, J., Stambolic, V., Pujana, M.A., Mak, T.W., et al. (2016). The acetyltransferase Tip60 contributes to mammary tumorigenesis by modulating DNA repair. Cell Death Differ. 23, 1198-1208.

Bennaceur-Griscelli, A., Bosq, J., Koscielny, S., Lefrère, F., Turhan, A., Brousse, N., Hermine, O., and Ribrag, V. (2004). High Level of Glutathione-S-Transferase $\pi$ Expression in Mantle Cell Lymphomas. Clin. Cancer Res.

Bentz, M., Plesch, A., Bullinger, L., Stilgenbauer, S., Ott, G., Müller-Hermelink, H.K., Baudis, M., Barth, T.F.E., Möller, P., Lichter, P., et al. (2000). t(11;14)-positive mantle cell lymphomas exhibit complex karyotypes and share similarities with B-cell chronic lymphocytic leukemia. Genes Chromosom. Cancer.

Bosch, F., Jares, P., Campo, E., Lopez-Guillermo, A., Piris, M.A., Villamor, N., Tassies, D., Jaffe, E.S., Montserrat, E., Rozman, C., et al. (1994). PRAD-1/cyclin D1 gene overexpression in chronic lymphoproliferative disorders: A highly specific marker of mantle cell lymphoma. Blood.

Camara-Clayette, V., Hermine, O., and Ribrag, V. (2012). Emerging agents for the treatment of mantle cell lymphoma. Expert Rev Anticancer Ther 12, 1205-1215.

Campo, E., and Rule, S. (2015). Mantle cell lymphoma: Evolving management strategies. Blood 125, 48-55. Covington, K.R., and Fuqua, S.A.W. (2014). Role of MTA2 in human cancer. Cancer Metastasis Rev. 33, 921928.

Degan, M., Doliana, R., Gloghini, A., Di Francia, R., Aldinucci, D., Mazzocut-Zecchin, L., Colombatti, A., Attadia, V., Carbone, A., and Gattei, V. (2002). A novel bcl-1/JH breakpoint from a patient affected by mantle cell lymphoma extends the major translocation cluster. J. Pathol. 197, 256-263.

Dreyling, M.H., Bullinger, L., Ott, G., Stilgenbauer, S., Müller-Hermelink, H.K., Bentz, M., Hiddemann, W., 
bioRxiv preprint doi: https://doi org/10.1101/2019.12.30.882407; this version posted April 15,2020 . The copyright holder for this preprin (which was not certified by peer review) is the author/funder, who has granted bioRxiv a license to display the preprint in perpetuity. It is made available under aCC-BY-NC-ND 4.0 International license.

and Döhner, H. (1997). Alterations of the cyclin D1/p16-pRB pathway in mantle cell lymphoma. Cancer Res. $57,4608-4614$.

Epperla, N., Hamadani, M., Fenske, T.S., and Costa, L.J. (2017). Incidence and survival trends in mantle cell lymphoma. Br. J. Haematol. 2006-2008.

Fiancette, R., Amin, R., Truffinet, V., Vincent-Fabert, C., Cogné, N., Cogné, M., and Denizot, Y. (2010). A myeloma translocation-like model associating CCND1 with the immunoglobulin heavy-chain locus 3' enhancers does not promote by itself B-cell malignancies. Leuk. Res.

Germini, D., Tsfasman, T., Klibi, M., El-Amine, R., Pichugin, A., Iarovaia, O. V., Bilhou-Nabera, C., Subra, F., Bou Saada, Y., Sukhanova, A., et al. (2017). HIV Tat induces a prolonged MYC relocalization next to IGH in circulating B-cells. Leukemia 31, 2515-2522.

Greisman, H.A., Lu, Z., Tsai, A.G., Greiner, T.C., Yi, H.S., and Lieber, M.R. (2012). IgH partner breakpoint sequences provide evidence that AID initiates $\mathrm{t}(11 ; 14)$ and $\mathrm{t}(8 ; 14)$ chromosomal breaks in mantle cell and Burkitt lymphomas. Blood 120, 2864-2867.

Grumolato, L., and Aaronson, S.A. (2014). Oncogenes and Signal Transduction. In The Molecular Basis of Cancer: Fourth Edition

Hanakahi, L. a, Dempsey, L. a, Li, M.J., and Maizels, N. (1997). Nucleolin is one component of the B cellspecific transcription factor and switch region binding protein, LR1. Proc. Natl. Acad. Sci. U. S. A. 94, 36053610 .

Harewood, L., and Fraser, P. (2014). The impact of chromosomal rearrangements on regulation of gene expression. Hum. Mol. Genet. 23.

Harewood, L., Schutz, F., Boyle, S., Perry, P., Delorenzi, M., Bickmore, W.A., and Reymond, A. (2010). The effect of translocation-induced nuclear reorganization on gene expression. Genome Res 20, 554-564.

Hartmann, E., Fernàndez, V., Moreno, V., Valls, J., Hernández, L., Bosch, F., Abrisqueta, P., Klapper, W., Dreyling, M., Hoster, E., et al. (2008). Five-gene model to predict survival in mantle-cell lymphoma using frozen or formalin-fixed, paraffin-embedded tissue. J. Clin. Oncol. 26, 4966-4972.

Hassan-Zadeh, V., Chilaka, S., Cadoret, J.C., Ma, M.K.W., Boggetto, N., West, A.G., and Prioleau, M.N. (2012). USF binding sequences from the HS4 insulator element impose early replication timing on a vertebrate replicator. PLoS Biol. 10.

Hirt, C., Schüler, F., Dölken, L., Schmidt, C.A., and Dölken, G. (2004). Low prevalence of circulating 
bioRxiv preprint doi: https://doi.org/10.1101/2019.12.30.882407; this version posted April 15, 2020. The copyright holder for this preprin (which was not certified by peer review) is the author/funder, who has granted bioRxiv a license to display the preprint in perpetuity. It is made available under aCC-BY-NC-ND 4.0 International license.

$\mathrm{t}(11 ; 14)(\mathrm{q} 13 ; \mathrm{q} 32)$-positive cells in the peripheral blood of healthy individuals as detected by real-time quantitative PCR. Blood.

Hoster, E., Dreyling, M., Klapper, W., Gisselbrecht, C., Van Hoof, A., Kluin-Nelemans, H.C., Pfreundschuh, M., Reiser, M., Metzner, B., Einsele, H., et al. (2008). A new prognostic index (MIPI) for patients with advanced-stage mantle cell lymphoma. Blood 111, 558-565.

Jares, P., Colomer, D., and Campo, E. (2012). Molecular pathogenesis of mantle cell lymphoma. J. Clin. Invest. $122,3416-3423$.

Ji, C., Zhao, Y., Kou, Y.-W., Shao, H., Guo, L., Bao, C.-H., Jiang, B.-C., Chen, X.-Y., Dai, J.-W., Tong, Y.-X., et al. (2017). Cathepsin F Knockdown Induces Proliferation and Inhibits Apoptosis in Gastric Cancer Cells. Oncol. Res. Featur. Preclin. Clin. Cancer Ther. 26, 83-93.

Kienle, D., Katzenberger, T., Ott, G., Saupe, D., Benner, A., Kohlhammer, H., Barth, T.F.E., Höller, S., Kalla, J., Rosenwald, A., et al. (2007). Quantitative gene expression deregulation in mantle-cell lymphoma: Correlation with clinical and biologic factors. J. Clin. Oncol. 25, 2770-2777.

Knackmuss, U., Lindner, S.E., Aneichyk, T., Kotkamp, B., Knust, Z., Villunger, A., and Herzog, S. (2016). MAP3K11 is a tumor suppressor targeted by the oncomiR miR-125b in early B cells. Cell Death Differ. 23, 242252.

Lee, J.W., Soung, Y.H., Kim, S.Y., Nam, S.W., Kim, C.J., Cho, Y.G., Lee, J.H., Kim, H.S., Park, W.S., Kim, S.H., et al. (2004). Inactivating mutations of proapoptotic Bad gene in human colon cancers. Carcinogenesis 25, $1371-1376$.

Li, J.Y., Gaillard, F., Moreau, A., Harousseau, J.L., Laboisse, C., Milpied, N., Bataille, R., and Avet-Loiseau, H. (1999). Detection of translocation $\mathrm{t}(11 ; 14)(\mathrm{q} 13 ; \mathrm{q} 32)$ in mantle cell lymphoma by fluorescence in situ hybridization. Am. J. Pathol.

Lieber, M.R. (2016). Mechanisms of human lymphoid chromosomal translocations. Nat. Rev. Cancer 16, $387-$ 398.

Liu, H., Huang, J., Wang, J., Jiang, S., Bailey, A.S., Goldman, D.C., Welcker, M., Bedell, V., Slovak, M.L., Clurman, B., et al. (2008). Transvection mediated by the translocated cyclin D1 locus in mantle cell lymphoma. J. Exp. Med. 205, 1843-1858.

Lovec, H., Grzeschiczek, A., Kowalski, M.B., and Möröy, T. (1994). Cyclin D1/bcl-1 cooperates with myc genes in the generation of B-cell lymphoma in transgenic mice. EMBO J. 
bioRxiv preprint doi: https://doi. org/10.1101/2019.12.30.882407; this version posted April 15, 2020. The copyright holder for this preprin (which was not certified by peer review) is the author/funder, who has granted bioRxiv a license to display the preprint in perpetuity. It is made available under aCC-BY-NC-ND 4.0 International license.

Meggendorfer, M., Kern, W., Haferlach, C., Haferlach, T., and Schnittger, S. (2013). SOX11 overexpression is a specific marker for mantle cell lymphoma and correlates with $\mathrm{t}(11 ; 14)$ translocation, CCND1 expression and an adverse prognosis. Leukemia 27, 2388-2391.

Melone, M.A.B., Valentino, A., Margarucci, S., Galderisi, U., Giordano, A., and Peluso, G. (2018). The carnitine system and cancer metabolic plasticity review-article. Cell Death Dis. 9.

Pasqualucci, L., Trifonov, V., Fabbri, G., Ma, J., Rossi, D., Chiarenza, A., Wells, V.A., Grunn, A., Messina, M., Elliot, O., et al. (2011). Analysis of the coding genome of diffuse large B-cell lymphoma. Nat. Genet. 43, 830837.

Peterson, J.F., Baughn, L.B., Ketterling, R.P., Pitel, B.A., Smoley, S.A., Vasmatzis, G., Smadbeck, J.B., Greipp, P.T., Mangaonkar, A.A., Thompson, C.A., et al. (2019). Characterization of a cryptic IGH/CCND1 rearrangement in a case of mantle cell lymphoma with negative CCND1 FISH studies. Blood Adv. 3, 12981302.

Razin, S. V., Gavrilov, A.A., Pichugin, A., Lipinski, M., Iarovaia, O. V., and Vassetzky, Y.S. (2011). Transcription factories in the context of the nuclear and genome organization. Nucleic Acids Res. 39, 90859092.

Rhind, N., and Gilbert, D.M. (2013). DNA Replication Timing. Cold Spring Harb. Perspect. Med. 3, 1-26.

Rivera-Mulia, J.C., Buckley, Q., Sasaki, T., Zimmerman, J., Didier, R.A., Nazor, K., Loring, J.F., Lian, Z., Weissman, S., Robins, A.J., et al. (2015). Dynamic changes in replication timing and gene expression during lineage specification of human pluripotent stem cells. Genome Res. 25, 1091-1103.

Rizzatti, E.G., Falcão, R.P., Panepucci, R.A., Proto-Siqueira, R., Anselmo-Lima, W.T., Okamoto, O.K., and Zago, M.A. (2005). Gene expression profiling of mantle cell lymphoma cells reveals aberrant expression of genes from the PI3K-AKT, WNT and TGF $\beta$ signalling pathways. Br. J. Haematol. 130, 516-526.

Rummel, M.J., De Vos, S., Hoelzer, D., Koeffler, H.P., and Hofmann, W.K. (2004). Altered apoptosis pathways in mantle cell lymphoma. Leuk. Lymphoma 45, 49-54.

Sakhdari, A., Ok, C.Y., Patel, K.P., Kanagal-Shamanna, R., Yin, C.C., Zuo, Z., Hu, S., Routbort, M.J., Luthra, R., Medeiros, L.J., et al. (2019). TP53 mutations are common in mantle cell lymphoma, including the indolent leukemic non-nodal variant. Ann. Diagn. Pathol. 41, 38-42.

Seidegård, J., and Ekström, G. (1997). The role of human glutathione transferases and epoxide hydrolases in the metabolism of xenobiotics. In Environmental Health Perspectives, pp. 791-799. 
bioRxiv preprint doi: https://doi.org/10.1101/2019.12 30.882407; this version posted April 15, 2020. The copyright holder for this preprint (which was not certified by peer review) is the author/funder, who has granted bioRxiv a license to display the preprint in perpetuity. It is made available under aCC-BY-NC-ND 4.0 International license.

Skarbnik, A.P., and Goy, A.H. (2015). Mantle cell lymphoma: state of the art. Clin. Adv. Hematol. Oncol. 13, $44-55$.

Thieblemont, C., Pack, S., Sakai, A., Beaty, M., Pak, E., Vortmeyer, A.O., Wellmann, A., Zhuang, Z., Jaffe, E.S., and Raffeld, M. (1999). Allelic loss of 11q13 as detected by MEN1-FISH is not associated with mutation of the MEN1 gene in lymphoid neoplasms. Leukemia 13, 85-91.

Vose, J.M. (2017). Mantle cell lymphoma: 2017 update on diagnosis, risk-stratification, and clinical management. Am. J. Hematol. 92, 806-813.

Yuan, Y., Qian, Z.R., Sano, T., Asa, S.L., Yamada, S., Kagawa, N., and Kudo, E. (2008). Reduction of GSTP1 expression by DNA methylation correlates with clinicopathological features in pituitary adenomas. Mod. Pathol. 21, 856-865. 


\section{A}

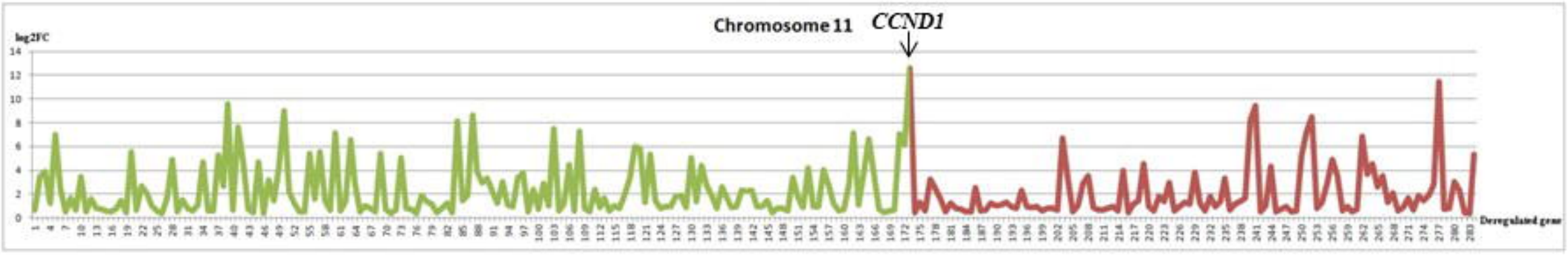

B

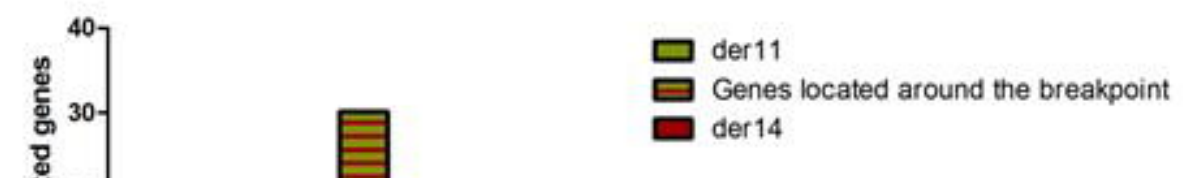

C

Chromosome 11: 55917447-84109244, 28.1 Mb

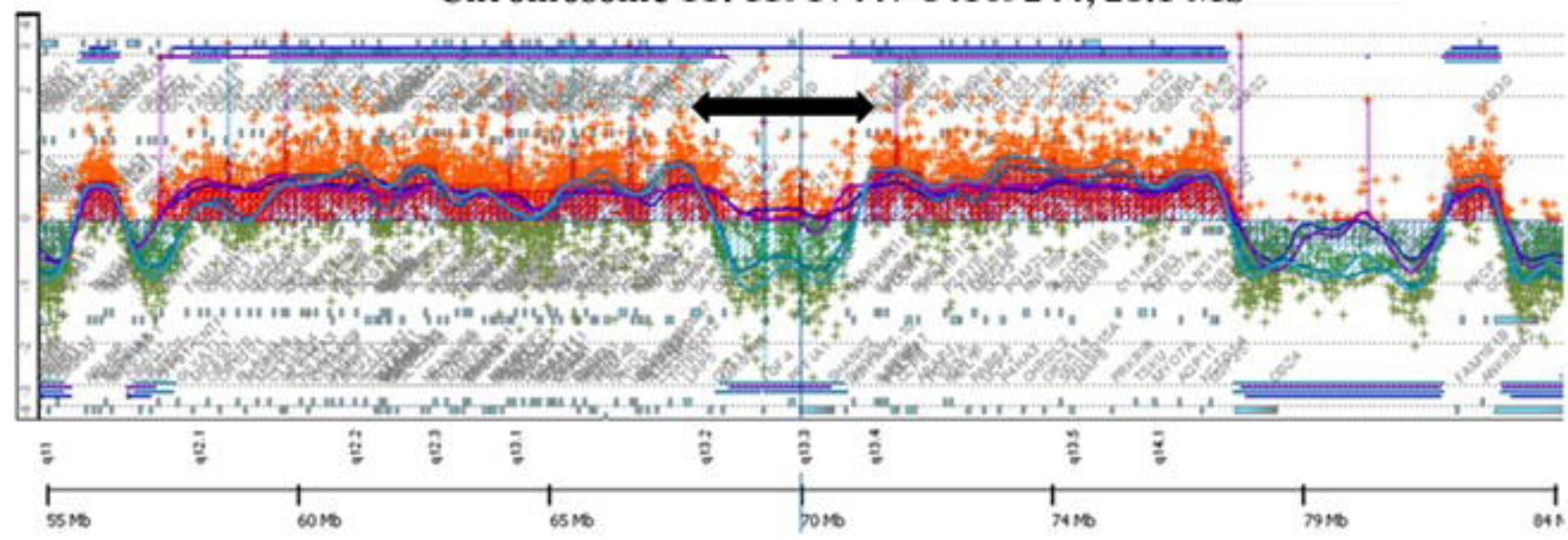

LCL RPMI8866

GRANTA-519 
Upregulated genes in GRANTA-519

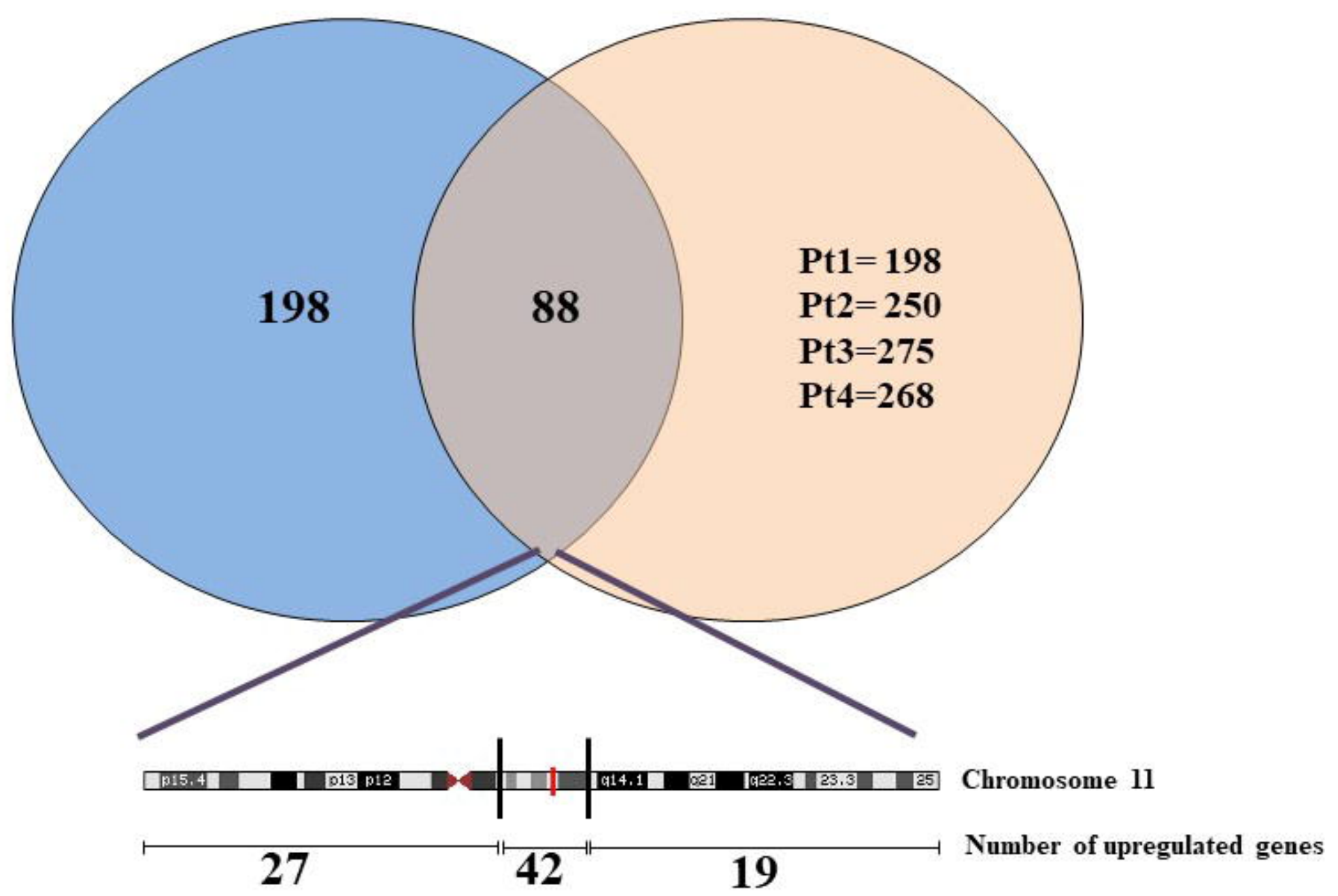


A $\quad$ Tel14 $/ G H$

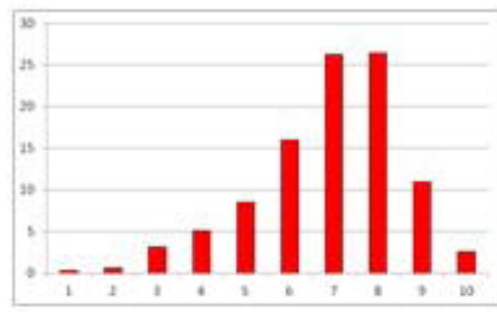

LCL RPMI8866

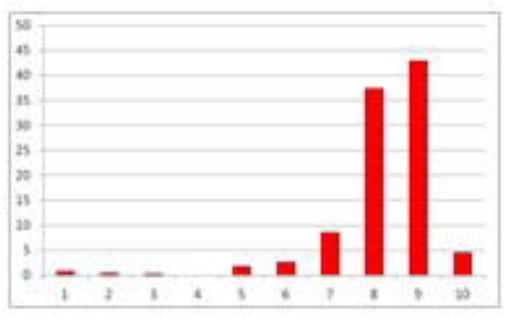

Granta 519
GSTP1
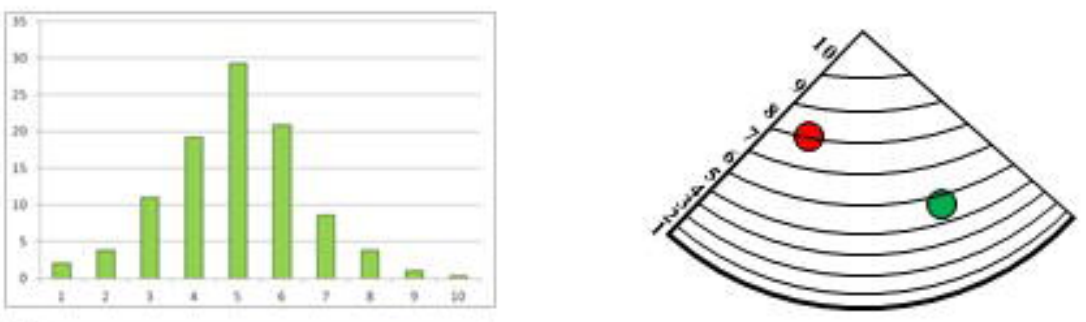

$-\ldots-m$ 目

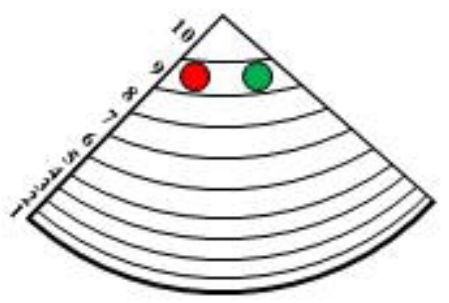

B

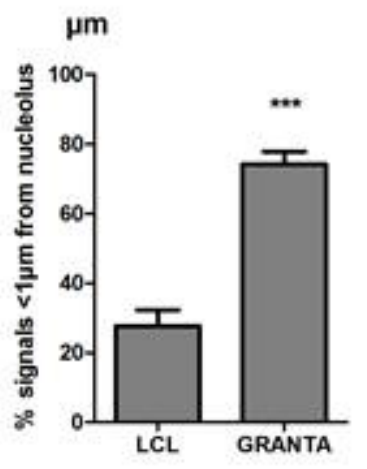

LCL RPMI 8866

C Tel14 (IGH)
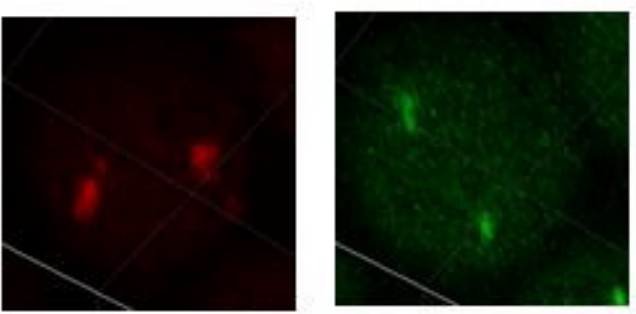

GRANTA 519
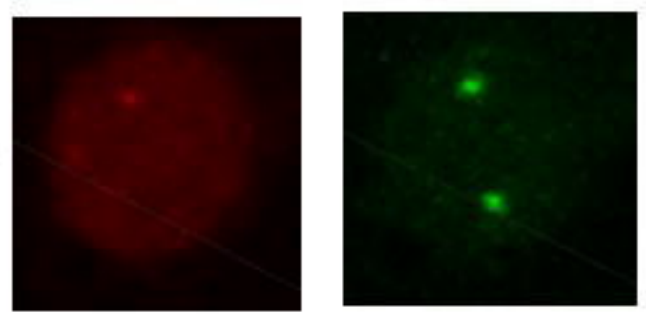

Nucleolin
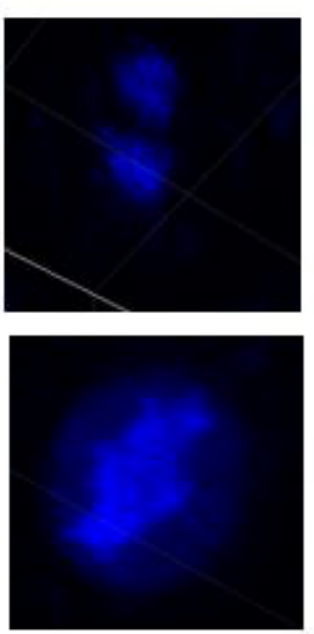

Merge
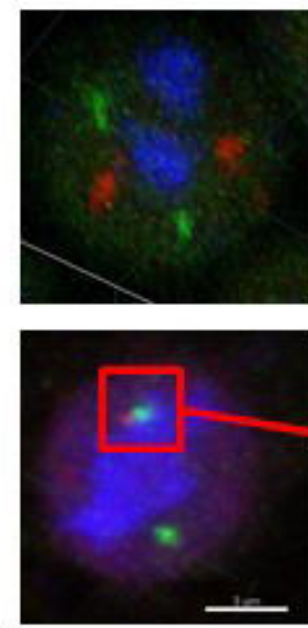
A

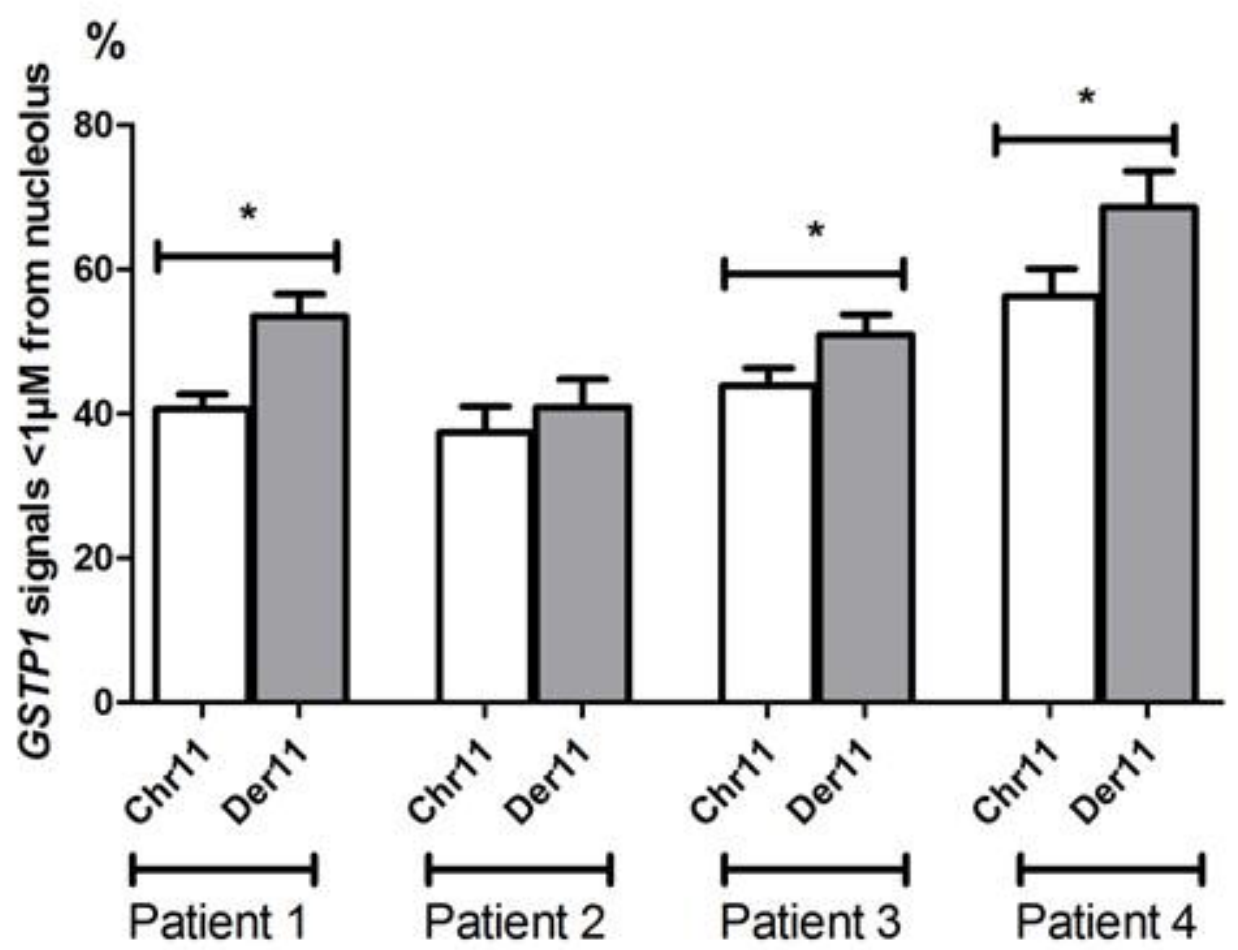

B

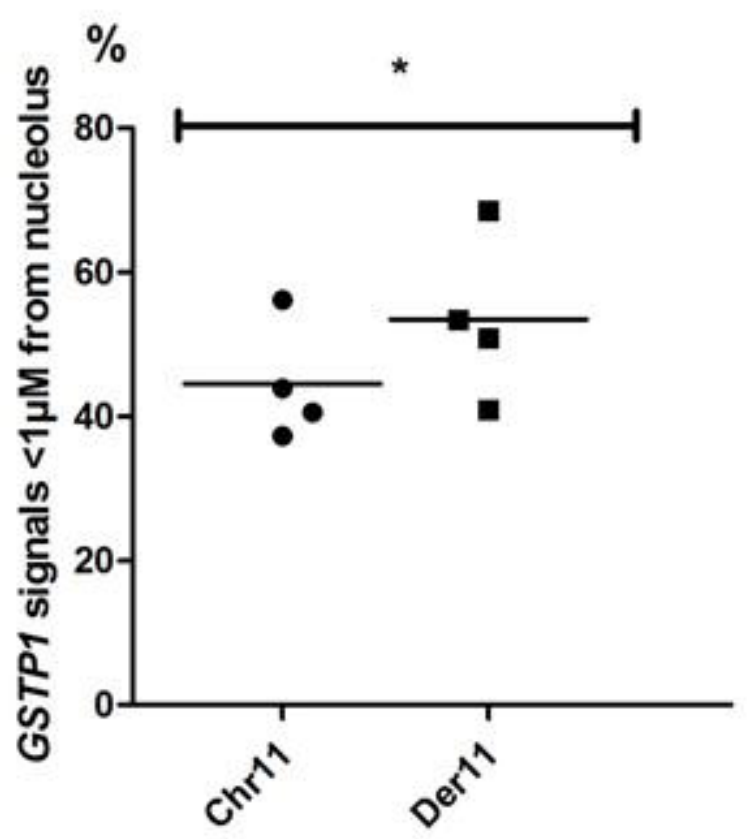




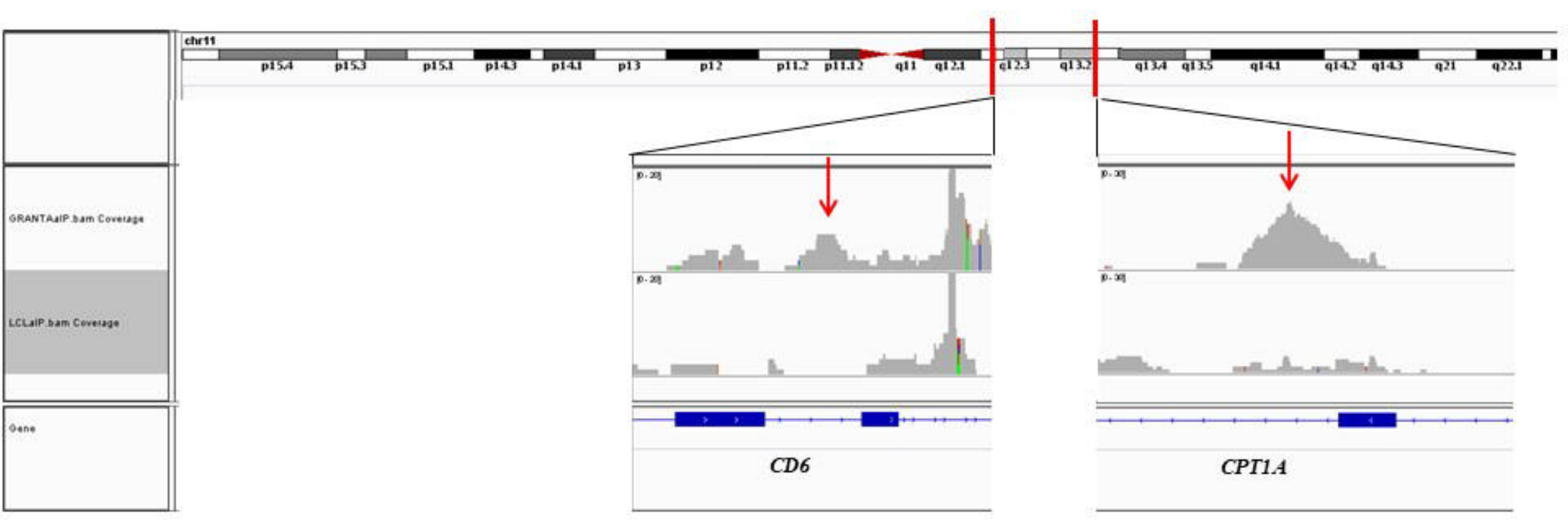


A

\section{Fold Change}

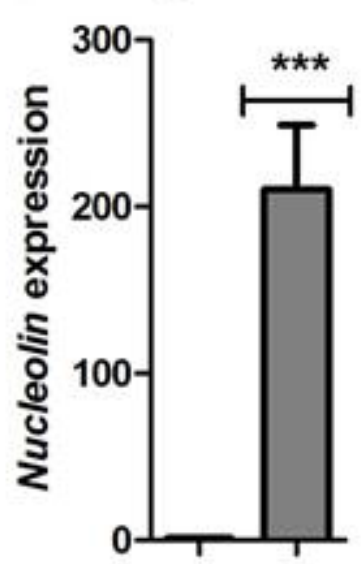

B

\section{Fold Change}

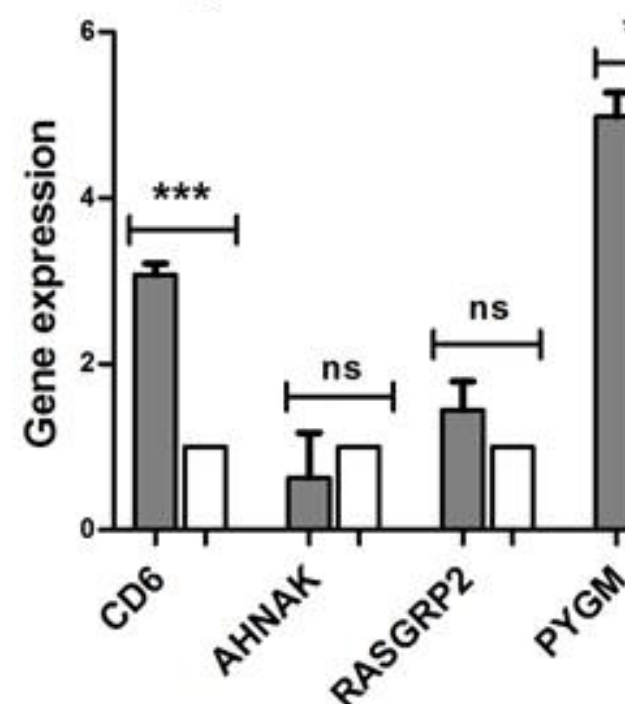

Hek

Hek-NucGFP 